\section{Varmus advises 'vow of chastity' over $\mathrm{NIH}$ staff consultancies}

Meredith Wadman, Washington

Senior staff at the National Institutes of Health (NIH) should be banned from most kinds of external consultancy work, according to the organization's former director Harold Varmus.

The suggestion, which would reverse rules that Varmus himself put in place in 1995, was made on 12 March to a blueribbon panel set up to examine conflictof-interest policy at the institutes. The panel was established after the Los Angeles Times suggested last December that some top NIH staff made biased decisions after receiving consultancy fees from drugs firms (see Nature 426, 741; 2003).

Varmus advised that senior staff take the same "vow of chastity" that he has taken in his current position as president of the Memorial SloanKettering Cancer Center in New York. "Institute directors should probably not be consulting for any companies," says Varmus. "And certainly not for companies that might be candidates for grants from the NIH." He also included institute deputy directors, scientific directors and clinical directors in the constrained group.

Varmus acknowledged that his recommendations would severely limit the outside activities of the most senior officials. But he said other staff, including most researchers, should be exempt in order to allow the NIH to recruit and retain the best scientists. The situation should automatically be reviewed if a researcher's outside earnings reached the same levels as his or her salary, he suggested.

Varmus loosened the rules in 1995, allowing institute directors to accept consulting payments from pharmaceutical firms, and removing a $\$ 25,000$ cap on outside earnings for all NIH employees. He also allowed employees to accept outside offers of stock and stock options, a payment seen as particularly prone to tempt scientists to bias results in favour of the companies employing them. Varmus believes times have now changed. "The interface between academia and industry has increased," he says.

The panel, which is chaired by Norman Augustine, chairman of engineering firm Lockheed Martin based in Bethesda, Maryland, and Bruce Alberts, president of the National Academy of Sciences, is due to report in May.

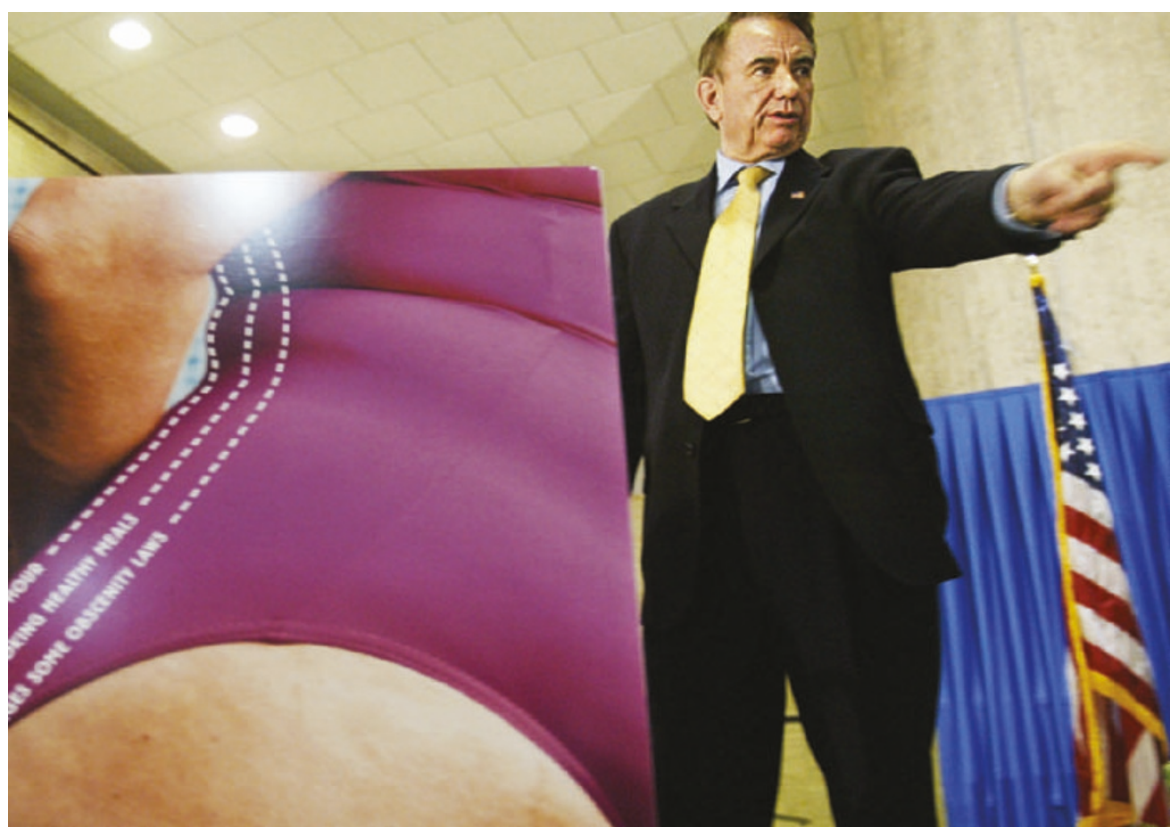

Fat chance: critics say NIH director Tommy Thompson's anti-obesity campaign is misdirected.

\title{
Health experts find obesity measures too lightweight
}

\section{Declan Butler}

Researchers have slammed the US government's plans to combat the country's obesity epidemic. Experts say the focus on changes in personal choices is flawed, and ignores the role of government and the food industry in shaping people's decisions.

The strategy, announced on 9 March by Tommy Thompson, head of the Department of Health and Human Services, combines a nationwide education and advertising campaign with a revamp of obesity research across the National Institutes of Health (NIH).

A public-awareness campaign, dubbed 'small steps', will try to educate Americans by highlighting healthier lifestyle options, such as walking up stairs instead of taking a lift. Thompson also wants voluntary measures to encourage restaurants to put calorie information on menus and to improve the accuracy of calorie counts on food labels.

Obesity experts say that education is fine, but they are angry that the government has not addressed what they believe to be the main cause of obesity - the easy availability of cheap, calorie-rich foods. For example, a study released last month by the Center for Science in the Public Interest, a Washingtonbased group that campaigns on nutrition issues, showed that the main courses of children's meals in US chain restaurants typically contain 700-900 calories, more than half the total recommended daily amount.

And according to a study by the Centers for Disease Control and Prevention in Atlanta, Georgia, around $64 \%$ of US citizens are overweight or obese (A. H. Mokdad et al. J. Am. Med. Assoc. 291, 1238-1245; 2004), with obesity accounting for 400,000 preventable deaths in 2000, second only to tobacco.

Regulating the food industry is the best way to tackle the problem, say public-health experts and nutrition scientists. They recommend banning soft drinks and fast foods in schools and food advertising directed at children. They also want compulsory labelling of the calorie content of restaurant menus.

"The campaign says nothing about what the government or the food industry could do to help people to eat less and move more," says Marion Nestle, chair of the Department of Nutrition, Food Studies and Public Health at New York University.

The other component of Thompson's plan - changes to NIH obesity research has been welcomed by obesity experts. Under the scheme, put together by a cross-agency task force set up by NIH director Elias Zerhouni, the institutes will focus on behavioural and environmental approaches to modifying lifestyle. It will also support clinical trials of diet strategies (see page 252).

Increased focus on research to prevent obesity is essential, says Kelly Brownell, director of Yale University's Center for Eating and Weight Disorders. He points out that the NIH has been criticized for focusing too much on the genetics, pharmacology and treatment of obesity. Research in these areas will continue under the plan, which could be funded by a $\$ 40$-million increase for obesity included in the 2005 NIH budget request.

But many scientists worry that marking obesity as a research problem risks'medicalizing' the issue and reinforcing public belief that it is a disease requiring treatment. 